\title{
Pengukuran Jarak Lubang Pada Benda Padat Menggunakan Sensor Ultrasonik
}

\author{
Ivan Dwicahyo Pratomo*1, Abdul Rouf ${ }^{2}$, Tri Wahyu Supardi ${ }^{3}$ \\ ${ }^{1}$ Prodi Elektronika dan Instrumentasi, Jurusan Ilmu Komputer dan Elektronika, FMIPA UGM \\ ${ }^{2,3}$ Jurusan Ilmu Komputer dan Elektronika, FMIPA UGM, Yogyakarta \\ e-mail: *11ivan182pratomo@gmail.com, ${ }^{2}$ rouf@mail.ugm.ac.id, ${ }^{3}$ twsupardi@ugm.ac.id
}

\begin{abstract}
Abstrak
Proses pembuatan benda padat pada umumnya, tidak tercetak dengan bagus sehingga bagian lubang tidak bisa dilihat langsung secara visual. NDT (Non Desctructive Testing) adalah metode untuk mendeteksi lubang serta menguji kualitas benda padat tanpa merusak benda padat tersebut salah satunya menggunakan ultrasonik untuk mendeteksi lubang benda padat yang terdapat pada bagian internal benda padat. Penelitian ini bertujuan untuk merancang bangun alat untuk mengukur jarak lubang pada benda padat menggunakan sensor ultrasonik dan osiloskop.

Metode yang digunakan penulis untuk pengujian merupakan metode pulsa pantul yang menghasilkan keluaran berupa amplitudo gelombang yang ditampilkan osiloskop. AFG sebagai masukkan pulsa $40 \mathrm{KHz}$ ke rangkaian penguat kemudian pulsa tersebut dikuatkan transformator dan dilanjutkan ke transmitter ultrasonik. Transmitter mengeluarkan pulsa ke objek dan mengalami pemantulan karena memiliki lubang pada internal bendanya. Pantulan tersebut diterima oleh receiver dan dikuatkan oleh rangkaian penguat kembali, kemudian gelombang ditampilkan pada osiloskop.

Penelitian ini menunjukkan bahwa semakin kecil jarak lubang maka amplitudo gelombang yang diperoleh menjadi semakin besar, ketika jarak lubang semakin besar maka nilai koefisien atenuasi bernilai semakin besar juga. Nilai kesalahan pada pengukuran menggunakan alat yang dibuat sebesar $5 \%$.
\end{abstract}

Kata kunci-ultrasonik, NDT (Non Destructive Testing), pulsa pantul, amplitudo

Abstract
The process of making solid object in general, not print with good so that holes can't be seen directly visually. NDT (Non Destructive Testing) is a method for detecting holes and the quality of solid objects without damaging solid object one uses ultrasonic to detect holes a solid object which there are on internal solid object. This research aims to design an instrument for measuring distances holes of solid body using ultrasonic sensor and oscilloscope.

The method used for the testing is the echo pulse which produce output of the wave amplitude shown oscilloscope. Function generator as input pulses $40 \mathrm{KHz}$ to circuit amplifier then the transformator strengthened and continued to ultrasonic transmitter. Transmitter generated pulse to object and the pulse has reflection because it has holes an internal object. The reflection pulse is received by the receiver ultrasonic sensor and amplified by signal amplifier circuit, then the wave displayed on oscilloscope.

The research showed that the smaller distance holes testing the wave amplitude obtained becomes larger and when the distance holes a solid object is longer the attenuation coefficient value the greater worth. The value of measurement error in using a tool value made author of $5 \%$.

Keywords - ultrasonic, NDT (Non Destructive Testing), echo pulse, amplitude 


\section{PENDAHULUAN}

$\mathrm{B}$ enda-benda di dunia ini seperti kayu, beton, air, udara, pensil, susu, kecap, balon dan yang lainnya. Dari bentuk wujudnya benda dapat dibedakan menjadi 3 macam, yakni benda padat, cair dan gas. Benda padat mempunyai contoh yakni, seperti kayu, beton, pensil. Benda cair mempunyai contoh yakni, seperti susu dan kecap. Benda gas mempunyai contoh balon dan udara yang kita hirup di dunia ini. Ketiga wujud benda tersebut mempunyai sifatnya masingmasing yang berbeda. Benda cair mempunyai sifat yakni: bentuknya tidak tetap, menekan ke segala arah, mengalir dari tempat yang tinggi ke tempat yang rendah, permukaannya yang selalu datar, dapat meresap melalui celah-celah kecil. Benda gas mempunyai sifat yakni : mempunyai bentuk dan volume sesuai dengan wadahnya dan menekan ke segala arah. Sedangkan benda padat mempunyai sifat yakni : memiliki berat, tidak merubah bentuk jika dipindahkan, bentuknya ada yang keras dan lembut serta benda padat dapat berubah wujud.

Benda padat sering digunakan pada kehidupan kita sehari-hari misalnya pada beton, batu bata, batako yang digunakan untuk pembangunan rumah, jembatan, gedung-gedung, kantor dan bangunan lainnya. Benda padat tersebut membuat bangunan menjadi lebih kokoh sehingga akan membuat bangunan tersebut tidak mudah hancur jika terkena suatu bencana. Pembuatan benda padat tersebut dibuat dengan mesin secara otomasi atau secara manual (tenaga manusia). Dari hasil cetakan benda padat, tidak semua cetakan tersebut tercetak dengan bagus, pasti ada saja bagian dari benda padat tersebut yang terdapat lubang pada bagian dalam dari benda padat tersebut sehingga membuat bahaya suatu bangunan jika menggunakan benda padat tersebut.

Ultrasonik dapat memungkinkan kita untuk mencari kecacatan pada suatu bahan material yang tersembunyi serta dapat digunakan juga untuk mengukur ketebalan bahan material tersebut [1].

Ultrasonik juga dapat digunakan untuk mendeteksi cacat permukaan yang rusak yang pada slot baja atau yang disebut dengan duralmunium [2].

Disamping itu, pemanfaatan ultrasonik sendiri mempunyai fungsi sebagai uji kualitas dari bahan padat tersebut sehingga nantinya ultrasonik akan mendapatkan data apakah benda padat tersebut mempunyai kualitas yang bagus atau tidak. Untuk mengukur jarak lubang pada benda padat digunakan metode pulsa pantul dari gelombang ultrasonik dengan perangkat osiloskop sebagai penampil gelombangnya sehingga keluaran gelombang ultrasonik dapat menembus permukaan benda yang memperoleh suatu nilai jarak lubang pada benda padat. Berbeda dengan menggunakan metode visual yang hanya dapat mendeteksi lubang atau kerusakan pada permukaan dari suatu benda padat.

\section{METODE PENELITIAN}

\subsection{Analisis Kebutuhan}

Gelombang ultrasonik merupakan gelombang mekanik sehingga dalam perambatannya membutuhkan medium perantara. Gelombang ultrasonik tidak dapat merambat pada ruang hampa sehingga proses transmisi pada ruang hampa tidak pernah terjadi. Gelombang ultrasonik memiliki frekuensi di atas jangkauan dengar manusia (di atas $20 \mathrm{kHz}$ ) [3].

Koefisien atenuasi merupakan besaran yang menyatakan kehilangan sejumlah energi karena gelombang melewati suatu medium. Besarnya energi yang hilang tergantung pada jenis mediumnya. Kehilangan energi disebabkan oleh beberapa hal yaitu kehilangan energi akibat adanya penyerapan oleh medium dan peristiwa gelombang pada bidang batas medium [3].

Pengukuran atenuasi gelombang ultrasonik dapat menggunakan persamaan (1)[4]:

$$
\alpha=\frac{1}{\Delta x}\left[\ln \frac{A_{\mathrm{o}}}{A}\right]
$$

IJEIS Vol. 6, No. 1, April 2016 : 81 - 92 
dengan $\alpha$ adalah nilai atenuasi gelombang, $\mathrm{A}_{0}$ merupakan amplitudo awal sebelum atenuasi, $\mathrm{A}$ adalah amplitudo yang meluruh setelah gelombang melalui jarak $\Delta \mathrm{x}$ dari lokasi awalnya (permukaan benda).

Kuantitas lain yang sering digunakan dalam pengukuran koefisien atenuasi adalah decibel (dB) yang dinyatakan dalam persamaan (2), sebagai perbandingan dari dua amplitudo pada skala logarithmic sebagai intensitas gelombang ultrasonik yang teratenuasi [5].

$$
\operatorname{Rasio}(\mathrm{dB})=20 \log _{10}\left[\frac{A_{\circ}}{A}\right]
$$

Dari persamaan (1) dan (2) serta konversi dari logaritma natural ke logaritma bilangan dasar sepuluh $(\ln (x)=2,303 \log (x)$, maka diperoleh persamaan (3) [5]:

$$
\begin{aligned}
& \alpha=\frac{1}{\Delta x} \ln \left(\frac{A_{\circ}}{A}\right) \\
& \alpha=\frac{1}{\Delta x} \frac{20}{2,303} \ln \left(\frac{A_{\circ}}{A}\right) \\
& \alpha=\frac{1}{\Delta x} 20 \log _{10}\left(\frac{A_{\circ}}{A}\right)
\end{aligned}
$$

Non Destructive Testing (NDT) adalah pengujian material tanpa menyebabkan kerusakan pada material tersebut. Pengujian ini bertujuan untuk mendeteksi dan menentukan lokasi, ukuran dan karakteristik lubang [6].

Metode pulsa Echo merupakan termasuk metode dari NDT menggunakan sensor ultrasonik bagian transmitter yang mengeluarkan sinyal ultrasonik dan receiver sensor ultrasonik akan menerima pulsa pantulan dari bahan padat untuk mendeteksi suatu lubang pada benda padat.

Inverting amplifier merupakan salah satu aplikasi Op-Amp yang paling umum digunakan karena sinyal keluarannya menghasilkan polaritas yang berkebalikan dengan sinyal masukkan dan penguatannya (gain) ditentukan oleh rasio antara resistor feedback (Rf) dengan resistor input (Ri). Gambar 1 berikut menggambarkan sebuah rangkaian Op-Amp yang digunakan sebagai inverting amplifier, dimana input non-inverting disambungkan dengan ground [7].

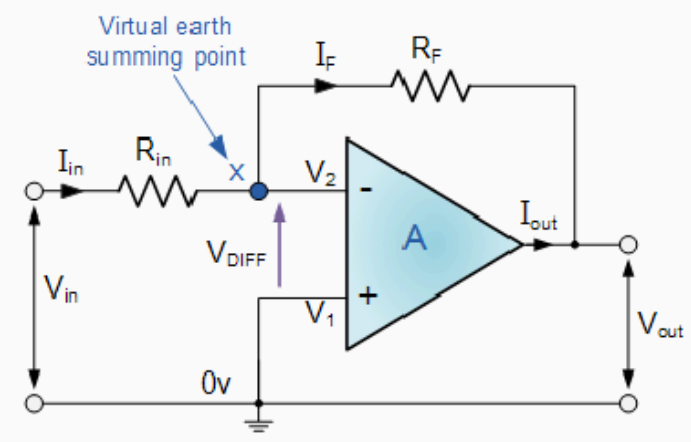

Gambar 1 Rangkaian Op-Amp sebagai Inverting Amplifier [6]

Dari Gambar 1 didapatkan persamaan (4):

$$
\begin{aligned}
& \text { Pada titik x didapatkan, } \quad \frac{V 2-V i n}{R i n}=\frac{\text { Vout }-V 2}{R f} \\
& \text { Karena } \mathrm{V} 1=\mathrm{V} 2=0, \text { maka Vout }=-\frac{R f}{\operatorname{Rin}}(\text { Vin })
\end{aligned}
$$

\subsection{Rancangan Sistem}

Sistem yang akan dirancang untuk penelitian ini merupakam sistem yang dapat melakukan pengukuran jarak lubang pada benda padat menggunakan sensor ultrasonik dengan metode pulsa pantul yang menggunakan osiloskop sebagai penampil gelombang keluaran dari sensor ultrasonik yang memperoleh informasi jarak lubang pada benda padat. Secara keseluruhan diagram blok sistem ini dapat dilihat pada Gambar 2 


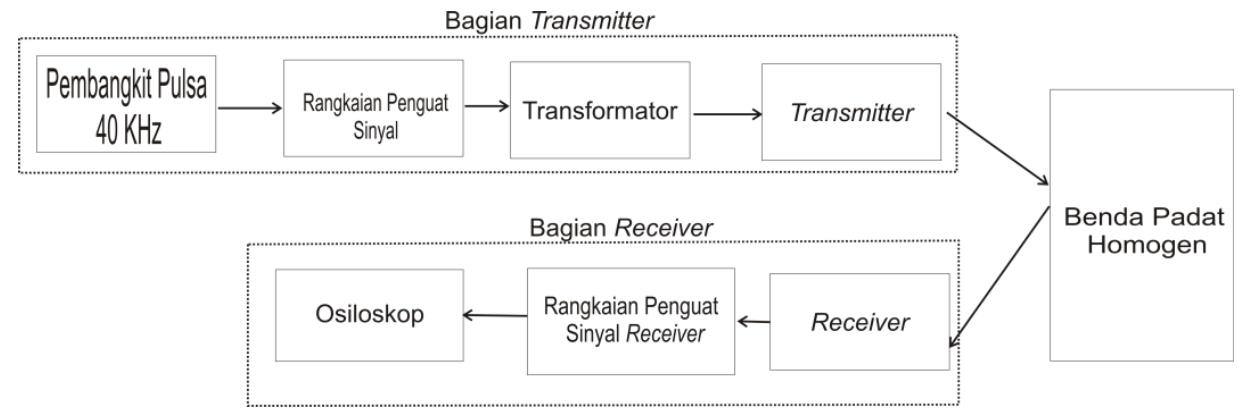

Gambar 2 Diagram blok sistem secara keseluruhan

Perangkat keras yang digunakan dalam sistem ini berupa sensor ultrasonik, osiloskop, pembangkit pulsa $40 \mathrm{KHz}$ serta beberapa rangkaian penguat. Sensor ultrasonik yang digunakan pada peneltian ini berupa dua buah probe yang berfungsi sebagai bagian transmitter dan receiver.

Pada bagian transmitter, Pembangkit pulsa $40 \mathrm{KHz}$ yang digunakan oleh penulis adalah AFG (Audio Function Generator). Pulsa $40 \mathrm{KHz}$ pancarkan oleh AFG menuju rangkaian audio amplifier LM 386. Pada rangkaian audio amplifier LM 386 mendapatkan sumber tegangan listrik dari catu daya $12 \mathrm{~V}$ yang dibuat oleh penulis. Rangkaian audio amplifier tersebut dapat menguatkan daya gelombang. Penguatan daya yang dilakukan seberapa besar nilai variabel resistor yang terdapat pada rangkaian. Jika variabel resistor diputar maka akan memperoleh gelombang sinus yang dapat terlihat jelas. Keluaran dari rangkaian audio amplifier dilanjutkan kedalam perangkat transformator step-up untuk dilakukan proses penguatan tegangan sehingga dihasilkan keluaran tegangan yang besar dari tegangan masukkannya. Keluaran dari transformator dilanjutkan ke transmitter sehingga transmitter memancarkan pulsa $40 \mathrm{KHz} \mathrm{ke}$ objek penelitian. Gambar 3 menunjukkan skematik rangkaian bagian transmitter.

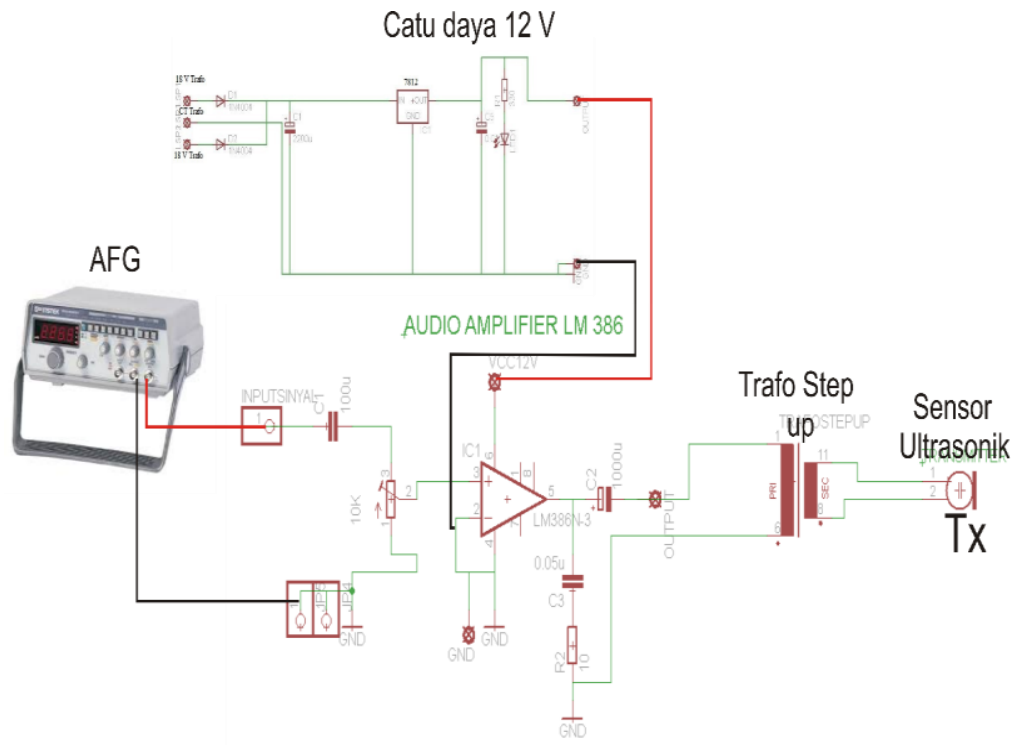

Gambar 3 Skematik Rangkaian Bagian Transmitter

Pulsa yang dipancarkan transmitter mengalami pantulan karena terdapat lubang di dalam internal objek penelitiannya. Pantulan tersebut akan diterima oleh receiver dan dilakukan penguatan oleh suatu rangkaian. Pada bagian receiver, untuk memperkuat daya dari pulsa yang diperoleh dari receiver, penulis menggunakan penguat IC LMC6032. IC LMC6032 terdapat pada modul SRF 04. Penulis menggunakan catu daya $5 \mathrm{~V}$ untuk mensuplai modul SRF 04. Hasil keluaran yang diterima receiver dan dilakukan penguatan, selanjutnya disambungkan pada 
probe osiloskop sehingga amplitudo gelombang yang diperoleh berdasarkan pengukuran jarak lubang pada benda padat. Skematik rangkaian bagian receiver dan osiloskop yang digunakan pada penelitian ini ditunjukkan pada Gambar 4.

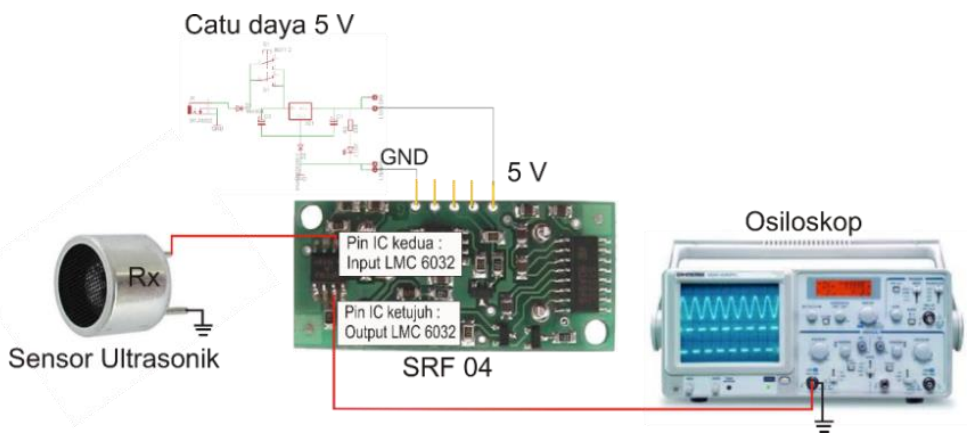

Gambar 4 Skematik Rangkaian Bagian Receiver dan Osiloskop

Rangkaian audio amplifier LM 386 digunakan penulis untuk menguatkan daya dari keluaran AFG menuju transmitter. . IC LM 386 merupakan IC audio amplifier yang dapat dioperasikan pada tegangan yang rendah, yakni: 5-12 V. Hasil penguatan dari IC ini tergantung konfigurasi rangkaian yang digunakan. Penguatan akan menjadi 20 kali apabila kaki IC satu dan delapan dalam keadaan terbuka sama seperti yang digunakan penulis pada penelitian ini Skematik rangkaian audio amplifier yang digunakan penulis ditunjukkan pada Gambar 5.

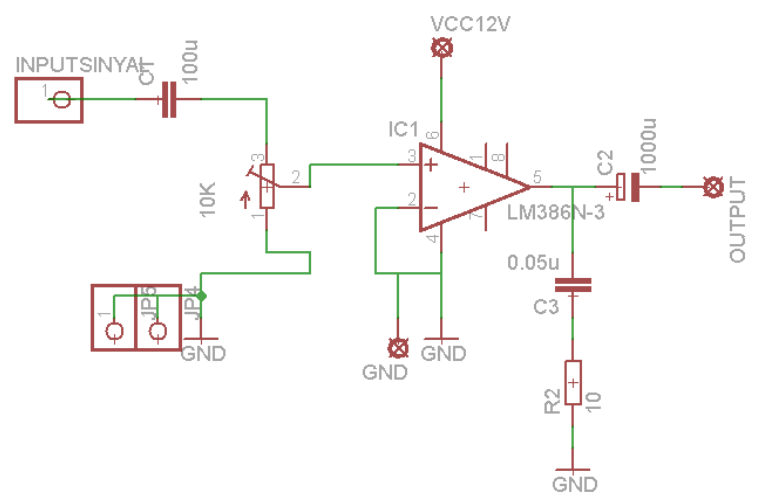

Gambar 5 Skematik Rangkaian Audio Amplifier LM 386

Pada rangkaian receiver yang terdapat pada modul SRF 04, terdapat dua buah op-amp di dalam IC LMC 6032. Kaki dua pada IC LMC 6032 sebagai masukan op-amp pertama dan kaki satu sebagai keluaran op-amp pertama. Kaki enam pada IC LMC 6032 sebagai masukan op-amp kedua dan kaki tujuh sebagai keluaran op-amp kedua. Gambar 6 menunjukkan rangkaian op-amp yang terdapat pada IC LMC 6032

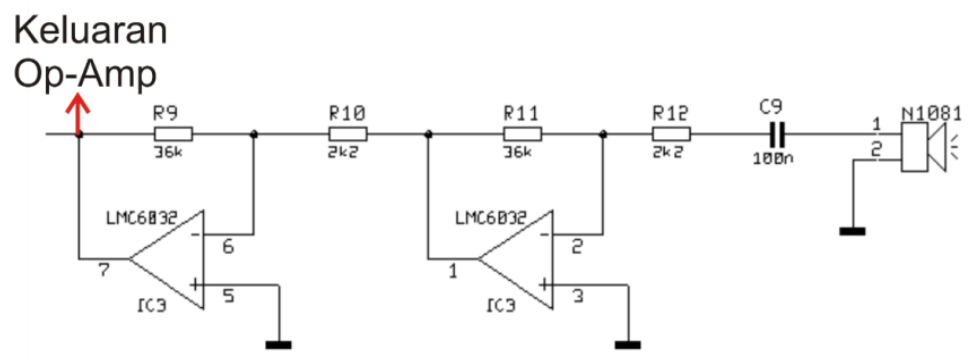

Gambar 6 Rangkaian Op-Amp di dalam IC LMC 6032 pada Modul SRF 04 
Menurut persamaan (4), maka dapat dihitung nilai penguatan dari Gambar 6 adalah :

$$
\begin{aligned}
& A v_{1}=-\frac{36 K}{2 K 2}=-16,363 \\
& \mathrm{Av}_{2}=-\frac{36 K}{2 K 2}=-16,363 \\
& \mathrm{Av} \text { Total }=\mathrm{Av}_{1} \times \mathrm{Av}_{2}=(-16,363) \times(-16,363) \\
& =267,74
\end{aligned}
$$

\subsection{Implementasi}

Implementasi elektronik pada sistem pendeteksi jarak ini terdiri dari rangkaian catu daya, rangkaian audio amplifier LM 386, rangkaian penguat IC LMC 6032. Penempatan elektronis diletakan pada bahan akrilik yang didesain oleh penulis untuk meletakkan beberapa rangkaian yang digunakan, seperti: rangkaian audio amplifier LM 386, modul SRF 04, transformator serta sensor ultrasonik yang digunakan sebagai transmitter dan receiver.

Gambar 7 menunjukkan board dari rangkaian audio amplifier LM 386 dan Gambar 8 menunjukkan implementasi elektronik yang ditempatkan pada akrilik yang sudah dibuat oleh penulis dari tampak atas.

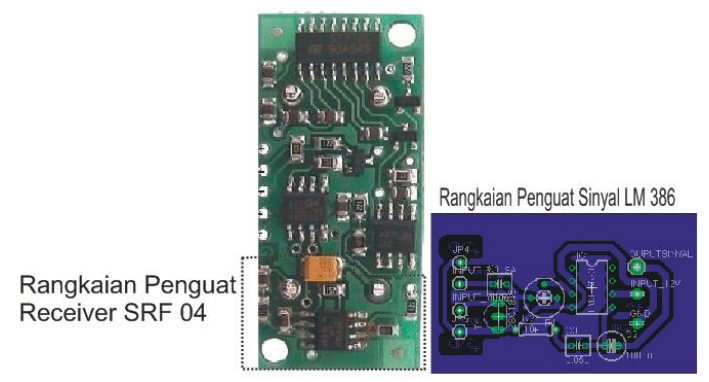

Gambar 7 Board Rangkaian Audio Amplifier LM 386 dan Modul SRF 04

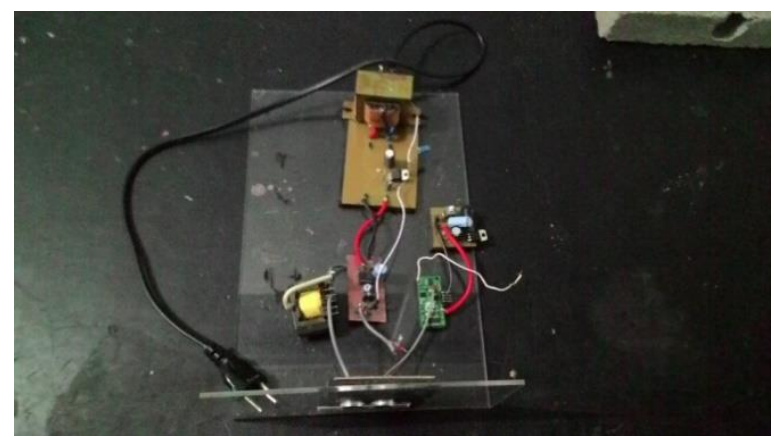

Gambar 8 Implementasi Elektronis Tampak Atas

Penulis membuat objek berdasarkan rancangan objek yang sudah rancangkan sebelumnya. Tabel 1 menunjukan ukuran objek penelitian yang sudah siap untuk dilakukan pengujian.

Tabel 1 Objek pengukuran penelitian

\begin{tabular}{|l|l|l|l|l|}
\hline Objek ke- & Panjang $(\mathrm{cm})$ & Lebar $(\mathrm{cm})$ & Tinggi $(\mathrm{cm})$ & Lubang $(\mathrm{cm})$ \\
\hline 1 & 11,3 & 9,5 & 8,2 & 3 \\
\hline 2 & 10,6 & 9,3 & 8,3 & 3,9 \\
\hline 3 & 10,8 & 9 & 8,7 & 1,3 \\
\hline 4 & 21 & 6,9 & 9 & \\
\hline
\end{tabular}

IJEIS Vol. 6, No. 1, April 2016: $81-92$ 
Keempat objek tersebut memiliki variasi jarak lubang pada benda padat yang berbedabeda sehingga pengukuran dapat dilakukan dengan enam variasi jarak, yaitu jarak lubang pada benda padat $1,3 \mathrm{~cm} ; 2,5 \mathrm{~cm} ; 3,0 \mathrm{~cm} ; 3,9 \mathrm{~cm} ; 5,0 \mathrm{~cm}$ serta jarak lubang pada benda padat yang belum diketeahui oleh penulis. Gambar 9 menunjukkan beton yang dibuat penulis dengan variasi jarak lubang yang berbeda dari tampak atas dan tampak depan serta objek penelitian yang belum diketahui jarak lubangnya.

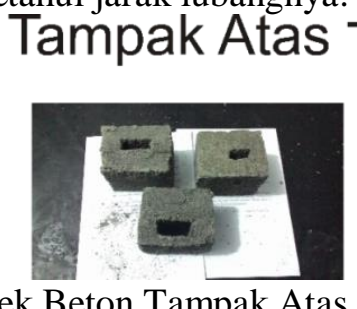

Gambar 9 Objek Beton Tampak Atas, Depan dan Objek yang Belum Diktehaui Jarak Lubang Benda Padat

\section{HASIL DAN PEMBAHASAN}

Penulis melakukan pengukuran jarak lubang pada benda padat menggunakan sensor ultrasonik dengan metode sudut pantul serta penggunaan osiloskop untuk penampil gelombang hasil keluaran sensor ultrasonik dengan menggunakan 6 variasi jarak lubang pada benda padat, yaitu : $1,3 \mathrm{~cm} ; 2,5 \mathrm{~cm} ; 3,0 \mathrm{~cm} ; 3,9 \mathrm{~cm} ; 5,0 \mathrm{~cm}$ dan jarak lubang yang belum diketahui oleh penulis.

\subsection{Pengujian pada Jarak Lubang 1,3 cm}

Pengujian ini dilakukan dengan variasi jarak lubang $1,3 \mathrm{~cm}$ pada objek penelitian berupa beton yang diulang sebanyak sepuluh kali. Nilai Volt/Div diatur $2 \mathrm{~V}$ dan Time/Div diatur pada nilai $10 \mu \mathrm{s}$. Dari data yang diperoleh, Gambar 10 menunjukkan salah satu tampilan amplitudo gelombang yang dihasilkan pada osiloskop.

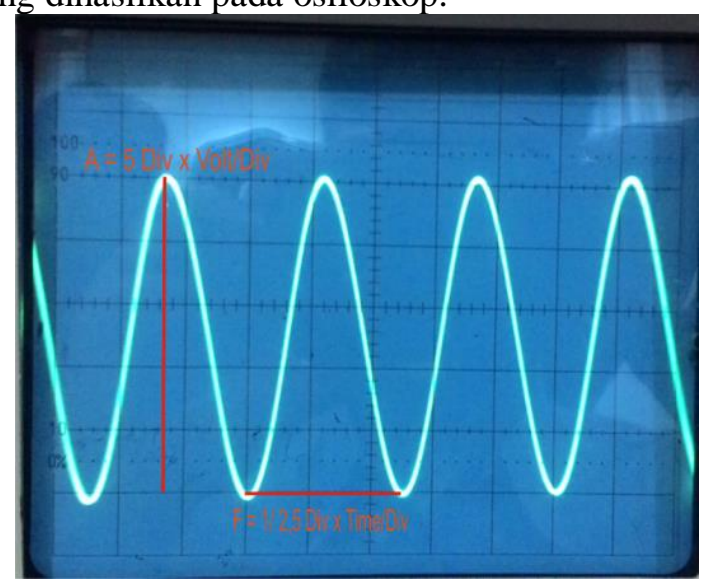

Gambar 10 Amplitudo Gelombang pada Osiloskop dengan Variasi Jarak Lubang pada Benda Padat $1,3 \mathrm{~cm}$

Dari Gambar 10 didapatkan amplitudo gelombang sebesar 5 Div sehingga bisa dilakukan perhitungan untuk mendapatkan besar nilai tegangan dari amplitudo dengan rumus:

$5 \operatorname{div} \times 2 \mathrm{~V}=10 \mathrm{~V}$.

Sehingga dari hasil tersebut diperoleh bahwa dari variasi jarak lubang $1,3 \mathrm{~cm}$ didapatkan besar tegangan sebesar $10 \mathrm{~V}$. Dari sepuluh kali pengujian yang dilakukan, diperoleh hasil rata-rata dari amplitudo pada jarak lubang $1,3 \mathrm{~cm}$ sebesar 10,3 V. 


\subsection{Pengujian pada Jarak Lubang 2,5 cm}

Pengujian kedua dilakukan dengan variasi jarak lubang $1,3 \mathrm{~cm}$ pada objek penelitian berupa beton yang diulang sebanyak sepuluh kali. Nilai Volt/Div diatur $1 \mathrm{~V}$ dan Time/Div diatur pada nilai $10 \mu \mathrm{s}$. Dari data yang diperoleh, Gambar 11 menunjukkan salah satu tampilan amplitudo gelombang yang dihasilkan pada osiloskop.

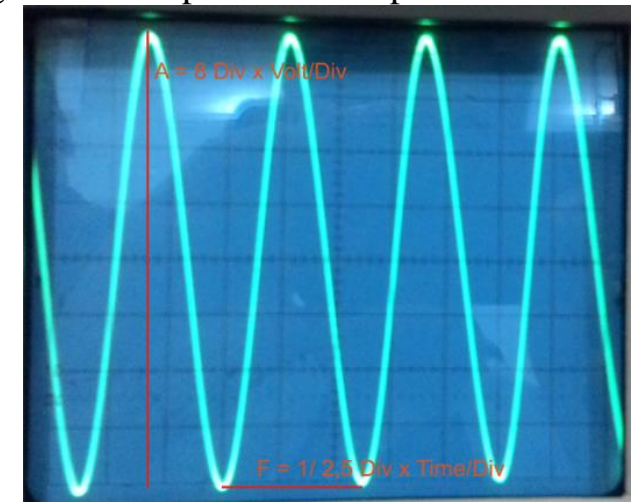

Gambar 11 Amplitudo Gelombang pada Osiloskop dengan Variasi Jarak Lubang pada Benda padat $2,5 \mathrm{~cm}$

Dari Gambar 11 didapatkan amplitudo gelombang sebesar 8 Div sehingga bisa dilakukan perhitungan untuk mendapatkan besar nilai tegangan dari amplitudo dengan rumus:

$8 \operatorname{div} \times 1 \mathrm{~V}=8 \mathrm{~V}$.

Sehingga dari hasil tersebut diperoleh bahwa dari variasi jarak lubang $2,5 \mathrm{~cm}$ didapatkan besar tegangan sebesar $8 \mathrm{~V}$. Dari sepuluh kali pengujian yang dilakukan, diperoleh hasil rata-rata dari amplitudo pada jarak lubang $1,3 \mathrm{~cm}$ sebesar $8,33 \mathrm{~V}$.

\subsection{Pengujian pada Jarak Lubang 3,0 cm}

Pengujian ketiga dilakukan dengan variasi jarak lubang 3,0 cm pada objek penelitian berupa beton yang diulang sebanyak sepuluh kali. Nilai Volt/Div diatur $1 \mathrm{~V}$ dan Time/Div diatur pada nilai $10 \mu \mathrm{s}$. Dari data yang diperoleh, Gambar 12 menunjukkan salah satu tampilan amplitudo gelombang yang dihasilkan pada osiloskop.

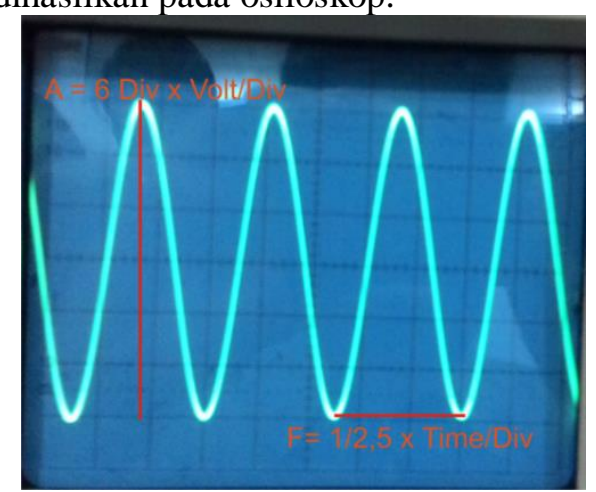

Gambar 12 Amplitudo Gelombang dengan Variasi Jarak Lubang pada Benda Padat 3,0 cm

Dari Gambar 12 didapatkan amplitudo gelombang sebesar 6 Div sehingga bisa dilakukan perhitungan untuk mendapatkan besar nilai tegangan dari amplitudo dengan rumus:

$6 \operatorname{div} \times 1 \mathrm{~V}=6 \mathrm{~V}$

Sehingga dari hasil tersebut diperoleh bahwa dari variasi jarak lubang $2,5 \mathrm{~cm}$ didapatkan besar tegangan sebesar 6 V. Dari sepuluh kali pengujian yang dilakukan, diperoleh hasil rata-rata dari amplitudo pada jarak lubang $1,3 \mathrm{~cm}$ sebesar $6,21 \mathrm{~V}$.

IJEIS Vol. 6, No. 1, April 2016 : $81-92$ 


\subsection{Pengujian pada Jarak Lubang 3,9 cm}

Pengujian keempat dilakukan dengan variasi jarak lubang 3,9 $\mathrm{cm}$ pada objek penelitian berupa beton yang diulang sebanyak sepuluh kali. Nilai Volt/Div diatur $1 \mathrm{~V}$ dan Time/Div diatur pada nilai $10 \mu \mathrm{s}$. Dari data yang diperoleh, Gambar 13 menunjukkan salah satu tampilan amplitudo gelombang yang dihasilkan pada osiloskop.

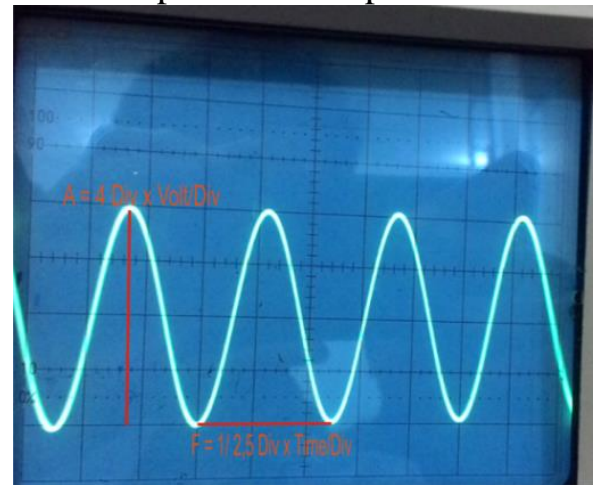

Gambar 13 Amplitudo Gelombang dengan Variasi Jarak 3,9 cm

Dari Gambar 13 didapatkan amplitudo gelombang sebesar 6 Div sehingga bisa dilakukan perhitungan untuk mendapatkan besar nilai tegangan dari amplitudo dengan rumus:

$$
4 \operatorname{div} \times 1 \mathrm{~V}=4 \mathrm{~V} \text {. }
$$

Sehingga dari hasil tersebut diperoleh bahwa dari variasi jarak lubang $3,9 \mathrm{~cm}$ didapatkan besar tegangan sebesar $4 \mathrm{~V}$. Dari sepuluh kali pengujian yang dilakukan, diperoleh hasil rata-rata dari amplitudo pada jarak lubang 3,9 cm sebesar 3,99 V.

\subsection{Pengujian pada Jarak Lubang 5,0 cm}

Pengujian kelima dilakukan dengan variasi jarak lubang 5,0 $\mathrm{cm}$ pada objek penelitian berupa beton yang diulang sebanyak sepuluh kali. Nilai Volt/Div diatur $1 \mathrm{~V}$ dan Time/Div diatur pada nilai $10 \mu \mathrm{s}$. Dari data yang diperoleh, Gambar 14 menunjukkan salah satu tampilan amplitudo gelombang yang dihasilkan pada osiloskop.

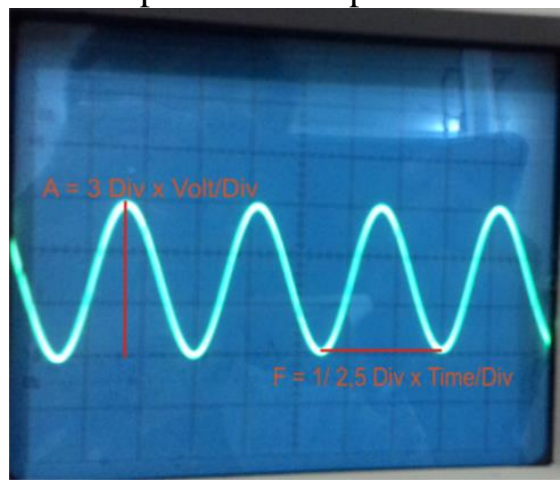

Gambar 14 Amplitudo Gelombang dengan Variasi Jarak Lubang pada Benda Padat 5,0 cm

Dari Gambar 14 didapatkan amplitudo gelombang sebesar 3 Div sehingga bisa dilakukan perhitungan untuk mendapatkan besar nilai tegangan dari amplitudo dengan rumus:

$$
3 \operatorname{div} x 1 \mathrm{~V}=3 \mathrm{~V} \text {. }
$$

Sehingga dari hasil tersebut diperoleh bahwa dari variasi jarak lubang $3,9 \mathrm{~cm}$ didapatkan besar tegangan sebesar $3 \mathrm{~V}$. Dari sepuluh kali pengujian yang dilakukan, diperoleh hasil rata-rata dari amplitudo pada jarak lubang 5,0 cm sebesar 2,9 V.

\subsection{Pengujian pada Jarak Lubang yang Belum Diketahui}

Pengujian keenam dilakukan dengan variasi jarak lubang yang belum diketahui pada objek penelitian berupa beton yang diulang sebanyak sepuluh kali. Nilai Volt/Div diatur $1 \mathrm{~V}$ 
dan Time/Div diatur pada nilai $5 \mu \mathrm{s}$. Dari data yang diperoleh, Gambar 15 menunjukkan salah satu tampilan amplitudo gelombang yang dihasilkan pada osiloskop dan proses pengujiannya.
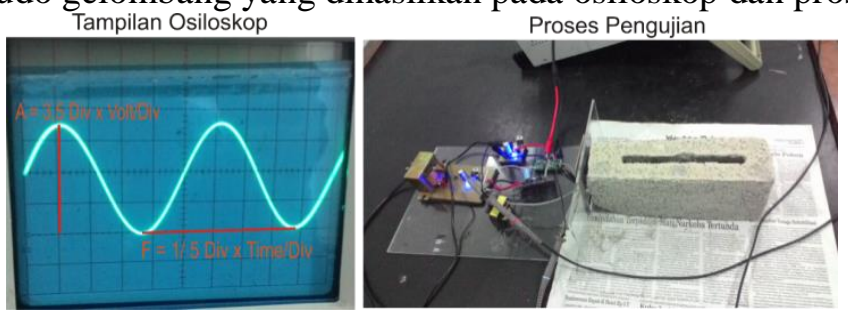

Gambar 15 Amplitudo Gelombang dengan Variasi Jarak Lubang yang Belum Diketahui dan Proses Pengujiannya

Dari Gambar 15 didapatkan amplitudo gelombang sebesar 3,5 Div sehingga bisa dilakukan perhitungan untuk mendapatkan besar nilai tegangan dari amplitudo dengan rumus:

$$
3,5 \operatorname{div} \times 1 \mathrm{~V}=3,5 \mathrm{~V} \text {. }
$$

Sehingga dari hasil tersebut diperoleh bahwa dari variasi jarak lubang yang belum diketahui didapatkan besar tegangan sebesar 3,5 V. Dari sepuluh kali pengujian yang dilakukan, diperoleh hasil rata-rata dari amplitudo pada jarak lubang yang belum diketahui sebesar 3,4 V.

Dari data yang diperoleh penulis mencari hubungan antara amplitudo dengan jarak lubang pada benda padat menggunakan nilai rata-rata amplitudo. Gambar 16 menunjukkan grafik hubungan antara rata-rata amplitudo vs jarak lubang pada benda padat.

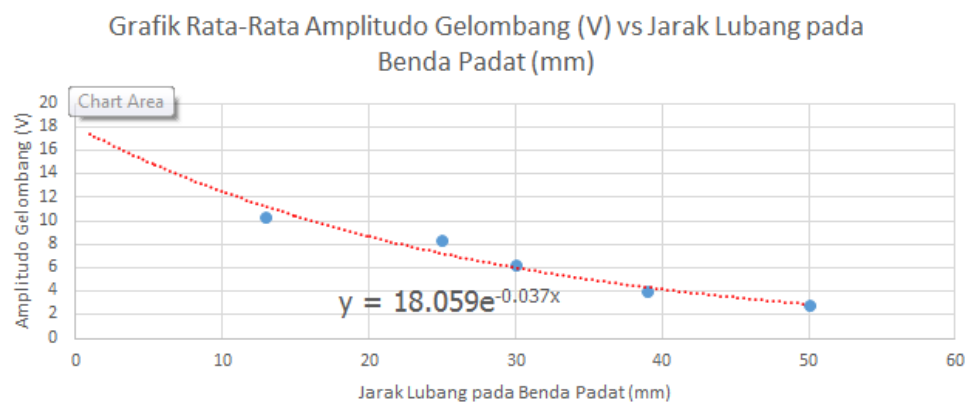

Gambar 16 Grafik Amplitudo Gelombang (V) vs Jarak Lubang dari Permukaan Benda Padat (mm)

Dari Gambar 16 didapatkan persamaan garis eksponensial yaitu $y=18,059 \mathrm{e}^{-0,037 \mathrm{x}}$. Persamaan garis yang diperoleh penulis dari hasil analisis data, hasil tersebut dapat menunjukkan bahwa semakin pendek jarak lubang pada benda padat yang ditempuh oleh gelombang ultrasonik maka nilai amplitudo yang diperoleh semakin besar, sehingga jika jarak lubang pada benda padat semakin panjang maka amplitudo yang diperoleh akan mendekati nilai nol (0).

Persamaan garis yang diperoleh juga bisa membuktikan berapa besar nilai kesalahan (error) pengukuran pada saat pengujian dengan menggunakan alat yang dibuat oleh penulis. Penulis menggunakan persamaan tersebut untuk mengetahui jarak lubang pada benda padat yang belum diketehui jarak lubangnya. Proses perhitungannya adalah :

$$
\begin{aligned}
& \mathrm{y}=18,059 \mathrm{e}^{-0,037 \mathrm{x}} \\
& \ln \mathrm{y}=\ln 18,059-0,037 \mathrm{x} \\
& 1,223=2,893-0,037 \mathrm{x} \\
& -1.67=-0,037 \mathrm{x} \\
& \mathrm{x}=45,15
\end{aligned}
$$

Dari perhitungan diatas , dimana:

$\mathrm{y}=$ nilai rata-rata ampiltudo

$\mathrm{x}=$ jarak lubang benda padat yang belum diketahui 
Penulis mengukur secara manual menggunakan penggaris untuk mengetahui jarak lubang pada benda padat yang belum diketahui sebagai nilai referensi untuk melakukan perbandingan antara jarak yang didapatkan dari perhitungan dengan jarak yang sebenarnya. Pengukuran jarak lubang yang diperoleh pada pengukuran tersebut menggunakan penggaris sebesar 4,3 $\mathrm{cm}$ atau $43 \mathrm{~mm}$. Hasil perhitungan menggunakan persamaan untuk mencari nilai $\mathrm{x}$, penulis mendapatkan jarak lubang pada benda padat sebesar $45,15 \mathrm{~mm}$.

Untuk mencari nilai eror dilakukan perhitungan dengan rumus :

Hasil perhitungan - jarak lubang sebenarnya $=$ hasil

1

$\frac{\text { Hasil }}{\text { Jarak sebenarnya }} \times 100 \%=$ Nilai kesalahan $($ error $)$

Nilai kesalahan (error) yang didapatkan penulis sebesar $5 \%$ sehingga pengukuran yang dilakukan sudah hampir mendekati jarak yang sebenarnya. Hasil error tersebut dapat dipengaruhi oleh benda padat yang dibuat penulis karena ada beberapa bagian benda padat yang tidak tercetak dengan rapi sehingga menyulitkan pengukuran yang dilakukan penulis dalam mengukur pulsa pantulan dari lubang yang terdapat pada internal benda padat.

Dari data yang diperoleh dengan besar nilai amplitudo gelombang pada lima variasi pengukuran jarak lubang pada benda padat yang dilakukan penulis, maka dapat dihitung juga nilai koefisen atenuasi pada pengujian dengan menggunakan persamaan (3). Hasil perhitungan yang didapat adalah :

Pengujian jarak lubang $1,3 \mathrm{~cm}=3,82 \mathrm{~dB} / \mathrm{cm}$

Pengujian jarak lubang $2,5 \mathrm{~cm}=5,66 \mathrm{~dB} / \mathrm{cm}$

Pengujian jarak lubang $3,0 \mathrm{~cm}=8,22 \mathrm{~dB} / \mathrm{cm}$

Pengujian jarak lubang $3,9 \mathrm{~cm}=12,06 \mathrm{~dB} / \mathrm{cm}$

Pengujian jarak lubang $3,9 \mathrm{~cm}=12,06 \mathrm{~dB} / \mathrm{cm}$

Pengujian jarak lubang $5,0 \mathrm{~cm}=14,83 \mathrm{~dB} / \mathrm{cm}$

Dari hasil tersebut penulis mendapatkan hubungan antara nilai koefisien atenuasi dengan jarak lubang pada benda padat. Gambar 17 menunjukkan grafik atenuasi (dB) vs jarak lubang pada benda padat $(\mathrm{cm})$ sesuai dengan persamaan (3).

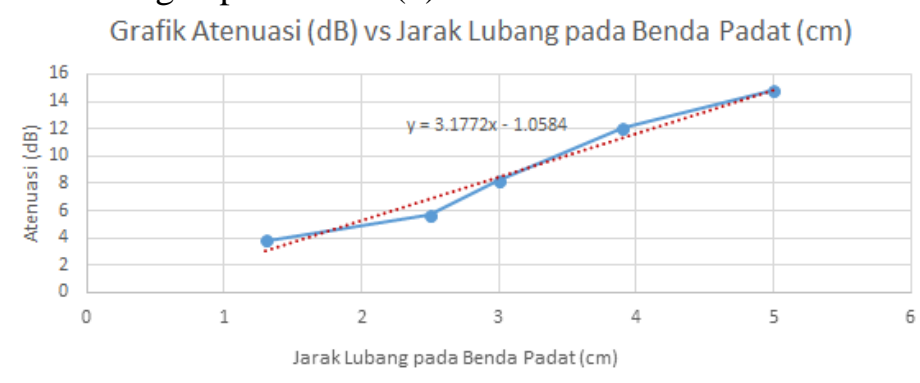

Gambar 17 Grafik Atenuasi (dB) vs Jarak Lubang pada Benda Padat (cm)

Dari Gambar 17 diperoleh persamaan garis $y=3,1772 x-1,0584$. Persamaan tersebut dapat disimpulkan bahwa semakin panjang jarak lubang pada benda padat maka nilai koefisien atenuasi semakin besar juga, hal ini disebabkan kedalaman jarak lubang pada benda padat yang ditempuh oleh suatu gelombang akan mengalami pelemahan gelombang karena adanya penyerapan oleh medium sehingga nilai koefisien atenuasi berbanding lurus dengan jarak lubang pada benda padat. 


\section{KESIMPULAN}

Dari hasil pengamatan, pengujian, dan analisis pada hasil yang diperoleh, kesimpulan sebagai berikut.

1. Telah berhasil merancang bangun alat untuk mengukur jarak lubang pada benda padat menggunakan sensor ultrasonik menggunakan metode pulsa pantul serta menggunakan osiloskop sebagai penampil gelombangnya.

2. Semakin pendek jarak lubang pada benda padat maka hasil tegangan dari amplitudo yang diperoleh semakin besar.

3. Semakin panjang jarak lubang pada benda padat maka nilai koefisien atenuasi semakin besar juga

4. Nilai kesalahan (error) pada pengukuran menggunakan alat yang dibuat sebesar $5 \%$

\section{SARAN}

Untuk penelitian selanjutnya, dicoba menggunakan mikrokontroler untuk mendapatkan hasil berupa waktu tempuh gelombang pada saat memantul objek penelitian serta membuat objek yang lebih halus lagi agar lebih mudah untuk melakukan pengujian.

\section{UCAPAN TERIMA KASIH}

Penulis mengucapkan terima kasih kepada semua pihak yang telah memberi dukungan baik secara moril maupun materiil terhadap penelitian ini.

\section{DAFTAR PUSTAKA}

[1] Mochalin, J.P. ,1998, Application of Wave Mixing in Photorefractive Materials to Laser Ultrasonics, Cleo, Friday Afternoon, 75 Bd de Mortagne, National Research Council, Canada.

[2] Clorennec, D. , Royer, D. dan Catheline, S., 2002, Saw Propagation on Cylindrical Part Using Laser Ultrasonics: Applications to Crack Detection, IEEE Ultrasonics Symposium, Perancis.

[3] Alfansuri, A. F., 2012, Identifikasi Chilling Injury Buah Alpukat (Persea Americana Mill) dengan Gelombang Ultrasonik, Skripsi, Fakultas Teknologi Pertanian, Institut Pertanian Bogor, Bogor.

[4] Treiber, M., 2008, Characterization of Cement-Based Multiphase Materials Using Ultrasonics Wave Attenuation, Tesis Master of Science in Engineering Science and Mechanics, Georgia Institute of Technology.

[5] Sugito, H. ,Suryono dan Layla, D., 2009, Aplikasi Transduser Ultrasonik Jenis Immersion Transducer untuk Karakteristik Media Cair dan Pengukuran Tingkat Kekasaran Beton, Berkala Fisika, No. 4, Vol. 12, Hal. 137-144.

[6] Subiyanto, L. dan Sardjono T. A., 2012, Deteksi Cacat Pada Material Baja Menggunakan Ultrasonik Non-Destructive Testing dengan Metode Continous Wavelet Transform, Seminar Nasional Teknologi Informasi dan Komunikasi Terapan, Semarang.

[7] Boylestad, R. L., dan Louis Nashelsky. Electronics Devices and Theory. New Jersey: Pearson Prentice Hall. 2006. Pp. 597-637.

IJEIS Vol. 6, No. 1, April 2016 : $81-92$ 